\title{
EWALT: East Meets West in a Multidisciplinary Setting to Improve the Management of Liver Tumors
}

\author{
Guido Torzillia Jean-Nicolas Vauthey ${ }^{b}$ Jacques Belghitic \\ Masatoshi Makuuchid Matteo Donadon ${ }^{\mathrm{a}}$ Luca Viganò $^{\mathrm{a}}$ \\ Norihiro Kokudo
}

\begin{abstract}
aDepartment of Surgery, Division of Hepatobiliary and General Surgery, Humanitas University, Humanitas Research Hospital, Milan, Italy, bDepartment of Surgical Oncology, The University of Texas, MD Anderson Cancer Center, Houston, Tex. USA, CHepato-Biliary and Pancreatic Surgery and Liver Transplantation Department, Beaujon Hospital, Assistance Publique-Hôpitaux de Paris, Paris VII University, Clichy, France, dDivisions of Hepato-Biliary-Pancreatic and Liver Transplantation Surgery,

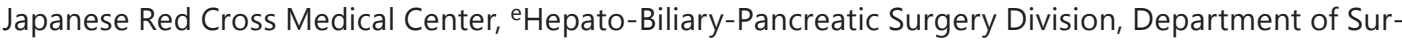
gery, Graduate School of Medicine, University of Tokyo, Tokyo, Japan
\end{abstract}

\author{
Key Words \\ Clinical trials · Hepatocellular carcinoma · Multidisciplinarity · Practice guidelines · Surgery
}

To stimulate debate between the two medical cultures, Jacques Belghiti and Masatoshi Makuuchi organized the first biennial Eastern and Western meeting focusing on hepatocellular carcinoma in 1998. Following the inaugural meeting in Paris, meetings took place in Tokyo, Lodi (Italy), Hong Kong, Houston, Seoul, Paris once again, and then Tokyo in 2013. Since that first meeting, the epidemiology of liver tumors has changed, new local treatments have been introduced, and already existing treatments have evolved. Systemic therapies have taken their place in the treatment of patients, and basic sciences have gradually assumed a role in clinical practice. These changes and advances have sometimes been interpreted differently in Eastern and Western medical practice. This has further stimulated the scientific discussion between the two hemispheres, strengthened the rationale for these meetings, and justified their expansion into the field of hepatobiliary oncology. Therefore, a new acronym was introduced to indicate the expanded interest in primary and metastatic hepatobiliary tumors: EWALT (Eastern and Western Association for the Study of Liver Tumors). The first EWALT meeting took place in Milan in 2015; over two and a half days, experts from East 
and West discussed innovations in the diagnosis and treatment of hepatocellular carcinoma, colorectal liver metastases, and biliary and neuroendocrine tumors.

These biennial meetings were initiated by surgeons, but multidisciplinarity infused an indispensable added value to each event. Rather than the development of guidelines, the purpose of the meetings was to give a voice to innovation: physicians can debate and exchange ideas, make suggestions, and offer constructive criticism to promote the optimal treatment of liver tumors. The meetings represent a laboratory for finding and testing new ideas and also for building a common vocabulary among specialists. The latter should minimize the chance of misunderstandings that could otherwise be a potential source of erroneous conclusions. The most clinically relevant example of the lack of commonality is the absence of an accepted definition of resectability for hepatocellular carcinoma, not only among different specialist fields, but also among surgeons [1]. While many alternatives to surgery have their own roles in selected unresectable patients, the definition of resectability should be a unique and reliable concept. Furthermore, many well-designed studies regarding nonsurgical approaches [2-4] have evolved into flawed criteria of unresectability, and treatment guidelines based on these studies [5] are currently in use. Furthermore, as a final paradox, these guidelines refer their recommendations to the general population, thereby including resectable subjects.

At the other end of this spectrum, the "diffusion phenomenon" of new surgical techniques has allowed a technique such as the associating liver partition and portal vein ligation for staged hepatectomy to become a new standard of care without previous clarification of basic aspects regarding eligibility criteria [6].

Agreement regarding these issues is of utmost importance. Innovation and rigorous methodology are not antithetical if the different languages used by different specialists can have a common vocabulary that facilitates insightful answers based on solid and commonly agreed principles. EWALT is the ideal multidisciplinary and international setting for this. The proceedings of previous meetings were published in indexed journals and highlighted the discussions and conclusions [7-10]. The current issue of Liver Cancer summarizes the EWALT 2015 meeting in Milan. We look forward to convening again in Sendai in January 2017 for the second EWALT meeting.

\section{Conflict of Interest}

The authors state that no conflicts of interest exist.

\section{References}

1 Folprecht G, Gruenberger T, Bechstein WO, Raab HR, Lordick F, Hartmann JT, Lang H, Frilling A, Stoehlmacher J, Weitz J, Konopke R, Stroszczynski C, Liersch T, Ockert D, Herrmann T, Goekkurt E, Parisi F, Köhne $\mathrm{CH}$ : Tumour response and secondary resectability of colorectal liver metastases following neoadjuvant chemotherapy with cetuximab: the CELIM randomised phase 2 trial. Lancet Oncol 2010;11:38-47.

2 Lo CM, Ngan H, Tso WK, Liu CL, Lam CM, Poon RT, Fan ST, Wong J: Randomized controlled trial of transarterial lipiodol chemoembolization for unresectable hepatocellular carcinoma. Hepatology 2002;35:11641171.

3 Llovet JM, Real MI, Montaña X, Planas R, Coll S, Aponte J, Ayuso C, Sala M, Muchart J, Solà R, Rodés J, Bruix J, Barcelona Liver Cancer Group: Arterial embolisation or chemoembolisation versus symptomatic treatment in patients with unresectable hepatocellular carcinoma: a randomised controlled trial. Lancet 2002;359:1734-1739. 
4 Llovet JM, Ricci S, Mazzaferro V, Hilgard P, Gane E, Blanc JF, de Oliveira AC, Santoro A, Raoul JL, Forner A, Schwartz M, Porta C, Zeuzem S, Bolondi L, Greten TF, Galle PR, Seitz JF, Borbath I, Häussinger D, Giannaris T, Shan M, Moscovici M, Voliotis D, Bruix J, SHARP Investigators Study Group: Sorafenib in advanced hepatocellular carcinoma. N Engl J Med 2008;359:378-390.

5 European Association for the Study of the Liver/European Organisation for Research and Treatment of Cancer: EASL-EORTC clinical practice guidelines: management of hepatocellular carcinoma. J Hepatol 2012;56:908-943.

6 Schadde E, Ardiles V, Robles-Campos R, Malago M, Machado M, Hernandez-Alejandro R, Soubrane O, Schnitzbauer AA, Raptis D, Tschuor C, Petrowsky H, De Santibanes E, Clavien PA, ALPPS Registry Group: Early survival and safety of ALPPS: first report of the International ALPPS Registry. Ann Surg 2014;260:829-836, discussion 836-838.

7 Hepatocellular Carcinoma: Eastern and Western Experiences. Proceedings of an international congress. Tokyo, Japan, December 9, 2000.Hepatogastroenterology 2002;49:5-95.

8 Oruc MT, Soran A, Jain AK, Wilson JW, Fung J: De novo breast cancer in patients with liver transplantation: University of Pittsburgh's experience and review of the literature. Liver Transpl 2004;10(suppl. 2):1-6.

9 Vauthey JN, Belghiti J, Makuuchi M: Proceedings of the Fifth International Meeting, Hepatocellular Carcinoma: Eastern and Western Experiences Overview of the Conference. Ann Surg Oncol 2008;15:961-1024.

10 Kokudo N, Sakamoto Y (eds): Hepatocellular Carcinoma. Eastern and Western Experiences. Liver Cancer 2013;2:1-68. 